\title{
Trend Analysis
}

National Cancer Institute

\section{Source}

National Cancer Institute. Trend Analysis. NCI Thesaurus. Code C139456.

The investigation involved trend analysis of adverse event of the actual device involved in the adverse event and/or of products from the same and/or different batches/lots. It should be noted that trend analysis typically is not considered sufficient as a stand-alone method, but should be used in conjunction with other investig ation methods for providing for instance complementary information. 